\title{
Review \\ Lot Streaming in Different Types of Production Processes: A PRISMA Systematic Review
}

\author{
Alexandra Salazar-Moya ${ }^{1}$ and Marcelo V. Garcia ${ }^{2, *(\mathbb{D})}$ \\ 1 Faculty of Systems, Electronics and Industrial Engineering, Universidad Técnica de Ambato, UTA, \\ Ambato 180206, Ecuador; psalazar5759@uta.edu.com \\ 2 Systems Engineering and Automation Department, University of the Basque Country, EHU/UPV, \\ 48013 Bilbao, Spain \\ * Correspondence: mgarcia294@ehu.es or mv.garcia@uta.edu.ec; Tel.: +593-998-267-906
}

check for

updates

Citation: Salazar-Moya, A.; Garcia, M.V. Lot Streaming in Different Types of Production Processes: A PRISMA Systematic Review. Designs 2021, 5, 67. https://doi.org/10.3390/ designs5040067

Academic Editors: Leonardo Marrazzini, Roberto Gabbrielli, Marcello Braglia, Marco Frosolini and Luca Padellini

Received: 17 August 2021

Accepted: 14 October 2021

Published: 19 October 2021

Publisher's Note: MDPI stays neutral with regard to jurisdictional claims in published maps and institutional affiliations.

Copyright: (C) 2021 by the authors. Licensee MDPI, Basel, Switzerland. This article is an open access article distributed under the terms and conditions of the Creative Commons Attribution (CC BY) license (https:// creativecommons.org/licenses/by/ $4.0 /)$.

\begin{abstract}
At present, any industry that wanted to be considered a vanguard must be willing to improve itself, developing innovative techniques to generate a competitive advantage against its direct competitors. Hence, many methods are employed to optimize production processes, such as Lot Streaming, which consists of partitioning the productive lots into overlapping small batches to reduce the overall operating times known as Makespan, reducing the delivery time to the final customer. This work proposes carrying out a systematic review following the PRISMA methodology to the existing literature in indexed databases that demonstrates the application of Lot Streaming in the different production systems, giving the scientific community a strong consultation tool, useful to validate the different important elements in the definition of the Makespan reduction objectives and their applicability in the industry. Two hundred papers were identified on the subject of this study. After applying a group of eligibility criteria, 63 articles were analyzed, concluding that Lot Streaming can be applied in different types of industrial processes, always keeping the main objective of reducing Makespan, becoming an excellent improvement tool, thanks to the use of different optimization algorithms, attached to the reality of each industry.
\end{abstract}

Keywords: lot streaming; productive process types; Makespan; optimization algorithms; PRISMA review

\section{Introduction}

Operations Management manages the processes that transform labor, capital, materials, information, and other inputs into products and services for the internal or external customer [1]. It defines the end of manufacturing industries, an environment that, due to its impact, deserves the effort to be identified, analyzed, and improved.

In the framework of Operations Management, it is critical for "Control", that is, to take actions to ensure success by meeting the objectives set, according to a plan, monitoring the costs, quality, and management of the allocated resources [2]. In this sense, we emphasize the control of the costs of production processes, insomuch as it ultimately determines the success or failure of an industry, because they cause an increment in the prices that the end customer must pay for the goods provided by the company [3].

Therefore, it was recognized that the management of production processes is essential; it is clear that any effort to continuously and dynamically improve them marks a constant change [4]. This improvement, in engineering terms, is a part of optimization representing technological and management decision-making to minimize the required effort or maximize the forecast profit by looking for conditions that give the maximum and minimum value of an objective function [5].

It was recognized that in the routine life of the industry, there are multiple drawbacks related to the delivery times of finished products to storage warehouses, and therefore, to the final consumer. After specific reviews, it is estimated that one of the fundamental 
reasons is the extensive operation and transfer lots making the control activities ineffective. Consequently, they do not help decrease the operation times and production costs, so this becomes an optimization objective.

This work presents a systematic literature review of one method to optimize the production processes-Lot Streaming (LS). This is the technique of splitting a production batch into smaller batches or transfer lots and processing them simultaneously on different machines remaining their movement through the processes or machine with the essential criterion of reducing the Makespan, i.e., the time elapsed from the start of the first operation of the first sublot on the first machine and the end of the last process of the latest sublot on the last machine [6].

This systematic review was carried out using the PRISMA (Preferred Reporting Items for Systematic Reviews and Meta-Analysis) methodology [7] to write scientific papers. In this case, for indexing documents that have DOI (Digital Object Identifier), with particular emphasis on the analytical reading of related publications, to carry out a comparative study of the different production systems in which the Lot Streaming was applied. However, it is recognized that only indexed publications and DOI may be restrictions on the research and bias the results obtained in a certain way.

There are previously published works that present literature reviews about Lot Streaming, such as Cheng et al. [8] and Chang et al. [9] that describe the particularities of the application with the different operational characteristics, or Gómez-Gasquet et al. [10] and Bagchi et al. [11] who analyze the LS specifically in the Flow Shop process, these being essential consultation tools. The present work generates a new source of consultation, which will allow future authors of further investigation on optimization process tools to have a greater insight into the most realistic environments to implement LS. According to the approaches reviewed in this paper, it offers a contrast of the main properties of the technique in question about the type of process in which it was applied, being able to carry out a new investigation on other strategies for optimizing production scheduling.

The following sections are detailed, Section 2 describing the methodology followed in selecting the cited articles, Section 3 describing the information found in scientific works and the results of the analyses about the crucial information, Section 4 where the research questions are answered, the conclusions build to after the conduct of this study, and the future research work based on the present learning, finally, Section 5 describes the sources of funding that supported the realization of the development presented.

\section{Methodology}

To achieve this systematic review, what was carried out in other systematic reviews was followed [12-14], and according to the PRISMA methodology, the following steps are followed: (i) research questions, (ii) sources of information, (iii) search strategy, (iv) eligibility criteria, (v) risk of bias, (vi) data extraction.

\subsection{Research Questions}

Four research questions were raised, which will support the proposed systematic analysis to verify the LS's usefulness to the calculation of the Makespan. These questions are framed in two thematic axes: (TA1) Applicability of LS; and (TA2) Solution and objective of the production scheduling problem. The proposed questions are given in Table 1.

The approach to these questions corresponds to a hierarchical tree, starting from the objectives proposed when selecting the research topic, progressing to essential issues that need to be validated. Starting from the need to solve a problem of programming and product flow, it is necessary to document a solution that can be applied in various specific production processes of industrial plants. Taking into account that LS forces us to "play" with processing batches, what classification or definition they obey must be analyzed in the first instance and reflected in the mathematical modeling that allows a calculation through an appropriate method, that is, a specifically focused algorithm, finally arriving at the demonstration of the objective of LS which is the decrease in the Makespan. 
Table 1. Research questions.

\begin{tabular}{|c|c|c|}
\hline $\mathbf{N}^{\circ}$ & Research Question & Motivation \\
\hline RQ1 & $\begin{array}{c}\text { In what types of production processes } \\
\text { has LS been applied? }\end{array}$ & $\begin{array}{l}\text { Identify the production processes in } \\
\text { which LS can be applied. }\end{array}$ \\
\hline RQ2 & For what types of sublots are LS used? & $\begin{array}{l}\text { Identify the different sublots to consider } \\
\text { in LS. }\end{array}$ \\
\hline RQ3 & $\begin{array}{l}\text { What optimization algorithms were used } \\
\text { for LS calculation? }\end{array}$ & $\begin{array}{c}\text { Identify the use of optimization } \\
\text { algorithms. }\end{array}$ \\
\hline RQ4 & Has LS been used to decrease Makespan? & Identify the LS's goal about Makespan. \\
\hline
\end{tabular}

\subsection{Sources of Information}

The research for scientific papers focuses on papers published in journals, so publications of congresses are deleted because the former is considered to reflect a greater strictness for publication acceptance. Searches were carried out in the academic research databases SCOPUS and IEEE Xplore, academics international editorials TAYLOR and FRANCIS and SPRINGER, search motor of academic publications SEMANTIC SCHOLAR and the online services of scientific research WEB OF SCIENCE and SCIENCE DIRECT, where indexed research that has DOI could be accessed to track the papers more efficiently.

\subsection{Search Methodology}

Research in the different digital media focuses on a combination of the following keywords: "Lot Streaming" AND ("production processes" OR "operating lots" OR "lead time reduction" OR "lot size" OR "algorithms of optimization "OR "Makespan" OR "decrease in the use of resources"), which must appear both in the title, in the keywords or in the summary of the analyzed papers (subsequent revision) refining the information limiting the publications to the time range indicated (2010-2020).

These sentences correspond to words related to the research questions indicated in Section 2.1, which allow discovering the investigations carried out, considering that the central axis is the "Lot Streaming", but that it is also required to know how applicable it is. Depending on the types of production processes, the batch sizes are essential to configure the methodology's usefulness analyzed in the operational reality. The application of the concept of optimization of the processes with the well-known objective of reducing the Makespan or the decrease in lead time leads to a decrease in the cost of production due to a decrease in resource use.

As shown in Table 2, the search concepts in all the databases consulted (7) adhered to the criteria described, where the mandatory field is "Lot Streaming", which is the investigated technique. A combination was generated (with the Boolean operator AND) with the important or determining aspects in the current research (with the Boolean operator OR) so that the initial concepts are complemented; in addition, the initial filter is set so that the articles have as publication date the years between 2010 and 2020, although it was indicated that the selected language is English; it is not necessary to indicate this filter because the articles found in the databases consulted are only published in that language.

Table 2. Search in digital databases and number of publications (initial search).

\begin{tabular}{|c|c|c|}
\hline Database & Search & Papers \\
\hline SCOPUS & $\begin{array}{l}\text { ("lot streaming"; AND ("production processes" OR “operation lots" } \\
\text { OR “decrease in lead time" OR “lot size" OR “optimization } \\
\text { algorithms" OR “Makespan" OR “decrease in resource use") AND } \\
\text { (LIMIT-TO (PUBYEAR, 2020) OR LIMIT-TO (PUBYEAR, 2019) OR } \\
\text { LIMIT-TO (PUBYEAR, 2018) OR LIMIT-TO (PUBYEAR, 2017) OR } \\
\text { LIMIT-TO (PUBYEAR, 2016) OR LIMIT- TO (PUBYEAR, 2015) OR } \\
\text { LIMIT-TO (PUBYEAR, 2014) OR LIMIT-TO (PUBYEAR, 2013) OR } \\
\text { LIMIT-TO (PUBYEAR, 2012) OR LIMIT-TO (PUBYEAR, 2011) OR } \\
\text { LIMIT-TO (PUBYEAR, 2010)). }\end{array}$ & 73 \\
\hline
\end{tabular}


Table 2. Cont.

\begin{tabular}{|c|c|c|}
\hline Database & Search & Papers \\
\hline $\begin{array}{l}\text { WEB OF } \\
\text { SCIENCE }\end{array}$ & $\begin{array}{c}\text { ("lot streaming" AND ("production processes" OR “operation } \\
\text { batches" OR "decrease in lead time" OR "lot size" OR } \\
\text { "optimization algorithms" OR “Makespan" OR “decrease in } \\
\text { resource use"). }\end{array}$ & 69 \\
\hline SCIENCEDIRECT & $\begin{array}{c}\text { ("lot streaming" AND ("production processes" OR “operation } \\
\text { batches" OR "decrease in lead time" OR "lot size" OR } \\
\text { "optimization algorithms" OR "Makespan" OR "decrease in } \\
\text { resource use"). }\end{array}$ & 25 \\
\hline $\begin{array}{l}\text { TAYLOR and } \\
\text { FRANCIS }\end{array}$ & $\begin{array}{l}\text { (All: "lot streaming") AND (All: "production processes") O (All: } \\
\text { "operation lots") O (All: "decrease in lead time") O (All: "lot size") } \\
\text { O (All: "optimization algorithms") OR (All: "Makespan") OR (All: } \\
\text { "decrease in resource use")) AND (Publication Date: (01/01/2010 } \\
\text { TO 12/31/2020)). }\end{array}$ & 19 \\
\hline IEEE & $\begin{array}{l}\text { ("lot streaming" AND ("production processes" OR "operation } \\
\text { batches" OR "decrease in lead time" OR "lot size" OR } \\
\text { "optimization algorithms" OR "Makespan" OR "decrease in } \\
\text { resource use"). }\end{array}$ & 4 \\
\hline $\begin{array}{l}\text { SEMANTIC } \\
\text { SCHOLAR }\end{array}$ & $\begin{array}{c}\text { ("lot streaming" AND ("production processes" OR "operation } \\
\text { batches" OR "decrease in lead time" OR "lot size" OR } \\
\text { "optimization algorithms" OR "Makespan" OR "decrease in } \\
\text { resource use"). }\end{array}$ & 7 \\
\hline SPRINGER & $\begin{array}{c}\text { ("lot streaming" AND ("production processes" OR “operation } \\
\text { batches" OR "decrease in lead time" OR "lot size" OR } \\
\text { "optimization algorithms" OR "Makespan" OR "decrease in } \\
\text { resource use"). }\end{array}$ & 3 \\
\hline Total & & 200 \\
\hline
\end{tabular}

\subsection{Eligibility Criteria}

Papers are selected in the first instance under the following criteria:

- Study design: All studies were included in which solutions to the Lot Streaming problem were outlined, and the literature reviews and comparative studies are discarded.

- Years considered: There are ten years, i.e., publications are reviewing from 2010 to 2020. Although there are previous papers, it is decided to limit the search in this way to present fresher information, in essence, due to this paper being based on previous studies.

- Language: English papers are searched as there are a more significant number of publications in that language.

- $\quad$ Publishing region: Papers from all regions of the world will be reviewed as this will result in further comparative analysis.

- Publication status: Papers published by indexed journals are considered, taking as a decisive factor of acceptance, with DOI (Digital Object Identifier).

\subsection{Risk of Bias in Individual Studies}

Understanding that bias in a study refers to a deviation in the information presented, either during the preparation or management of the information [15], to assess the possible bias for each paper, the Cochrane collaboration tool is used to assess the risk of bias (Table 8.5.a of the Cochrane Manual) [16]. This information judges whether there is a risk of bias in each of the six domains, classified as "high risk" or "low risk". Additional weight is given to the year of publication (rating scale) and the number of citations that the studies submitted at the time of the respective research. These three values are then multiplied by each other, and those studies with the highest value are those considered eligible for analysis and to be part of this paper. 


\subsection{Selection of Studies}

Only the author of this research participates in the selection of the papers following four stages. In the first stage, there was a choice of papers according to the "Lot Streaming" theme. In the second stage, duplicate papers were eliminated, with 94 items left. In the third stage, the papers were selected according to the type of study, eliminating case studies and reviews, which meant 71 papers were moved on to the next stage. In the fourth stage, the papers were selected by the lower risk of bias presented according to the rule designed, which meant 63 papers were accepted for final analysis. This selection scheme is shown in Figure 1 that presents the PRISMA flowchart for this selection of papers.

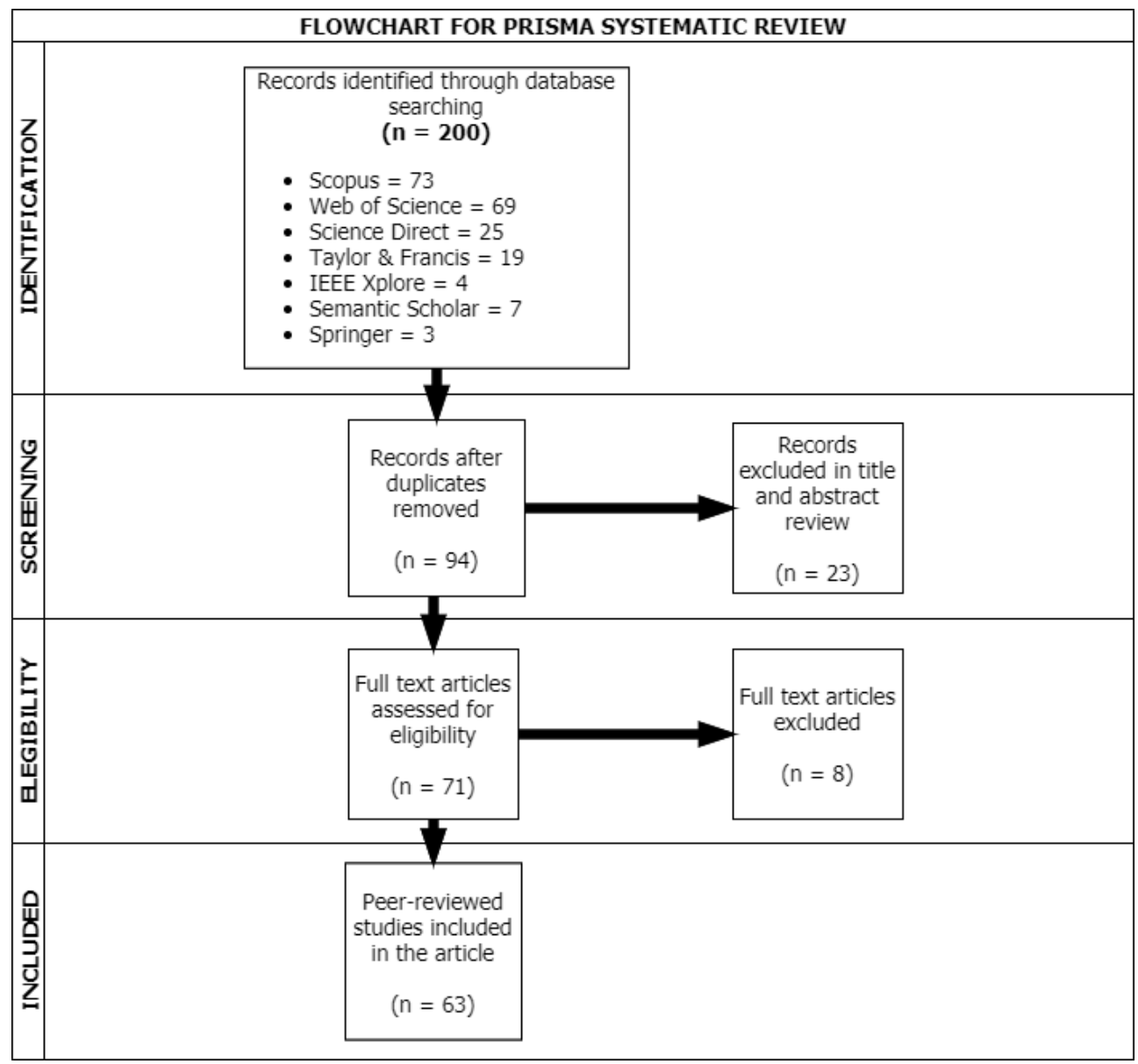

Figure 1. Flowchart for PRISMA systematic reviews.

\section{Results}

Data to be reviewed schematically and statistically (comparison) are mainly focused on answering the research questions; however, it is considered that other scopes are worth analyzing. To better understand these scopes, they were divided into three subcategories: the initial data that are the basic scopes when reviewing research, background data or weight factors to be analyzed, and the final data or conclusive aspects in the revised papers. The data that were framed in each subcategory are detailed in Table 3. 
Table 3. Data to be analyzed.

\begin{tabular}{|c|c|c|}
\hline Initial Data & Background Data & Final Data \\
\hline $\begin{array}{ll}\text { 1. } & \text { Base } \\
\text { 2. } & \text { Year } \\
\text { 3. } & \text { Country }\end{array}$ & $\begin{array}{ll}\text { 1. } & \text { Problem/type of production process studied } \\
\text { 2. } & \text { Additional features and times } \\
\text { 3. } & \text { Configuration/work number-machines } \\
\text { 4. } & \text { Types of sublots } \\
\text { 5. } & \text { Idling } \\
\text { 6. } & \text { Buffer } \\
\text { 7. } & \text { Setup Time } \\
\text { 8. } & \text { Objectives } \\
\text { 9. } & \text { Calculating the problem solution } \\
\text { 10. } & \text { Software for solving the problem } \\
\text { 11. } & \text { Compared to } \\
\text { 12. } & \text { Metrics to evaluate }\end{array}$ & $\begin{array}{ll}\text { 1. } & \text { Conclusion } \\
\text { 2. } & \text { Future works }\end{array}$ \\
\hline
\end{tabular}

\subsection{Initial Data}

\subsubsection{Base}

Even though seven databases were consulted, once the duplicate papers were deleted, prioritizing the basis where the most significant number of citations is located, only three databases were keeping up. These databases were Scopus with 56 papers, i.e., $89 \%$ of the papers referenced, Web of Science with five papers or $8 \%$, and Science Direct with two papers, which was $3 \%$ of selected papers.

\subsubsection{Year}

As noted, the range of years considered for publications ranges was from 2010 to 2020; the distribution of papers according to the year of publication is shown in Figure 2.

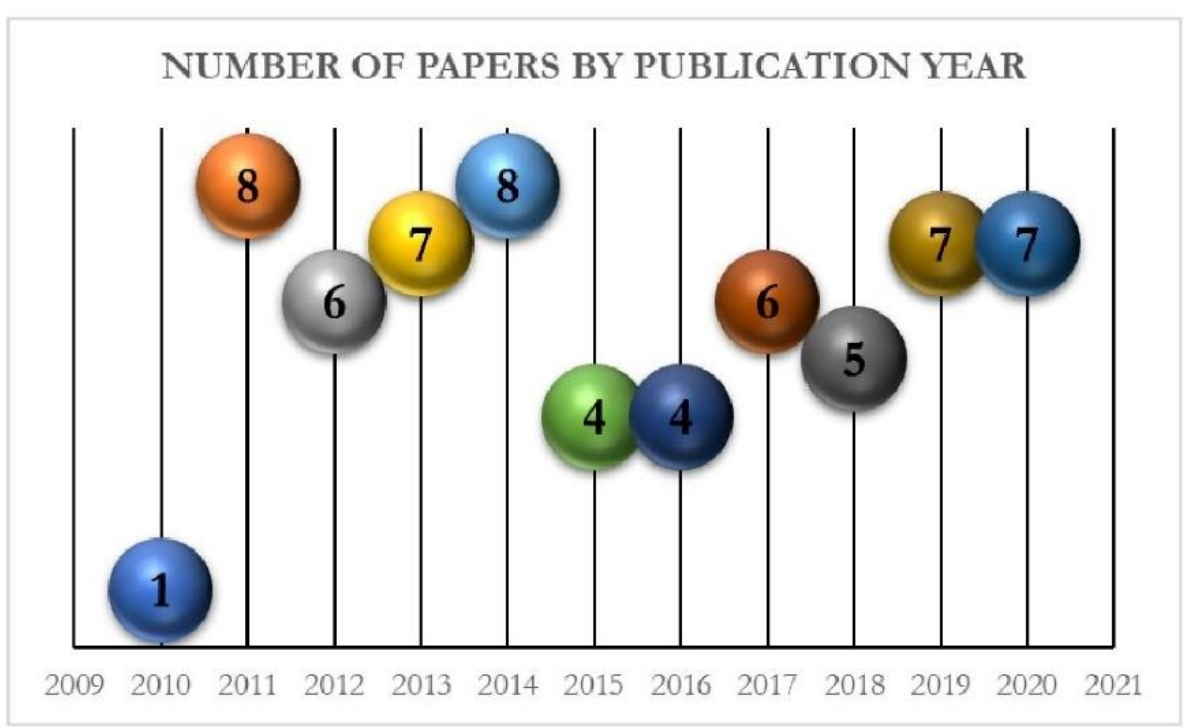

Figure 2. Number of papers by year of publication.

\subsubsection{Country}

The analyzed papers are distributed in 16 countries, listed in Table 4, and whose distribution around the world can be shown in Figure 3. 
Table 4. Number of papers by country.

\begin{tabular}{ccc}
\hline Country & Number of Papers & $\%$ \\
\hline China & 27 & $43 \%$ \\
Canada & 5 & $8 \%$ \\
Iran & 4 & $6 \%$ \\
USA & 4 & $6 \%$ \\
India & 3 & $5 \%$ \\
Argentina & 3 & $5 \%$ \\
Turkey & 3 & $5 \%$ \\
Malaysia & 3 & $5 \%$ \\
Taiwan & 2 & $3 \%$ \\
Germany & 2 & $3 \%$ \\
Czech Republic & 2 & $3 \%$ \\
Singapore & 1 & $2 \%$ \\
Colombia & 1 & $2 \%$ \\
South Korea & 1 & $2 \%$ \\
United Kingdom & 1 & $2 \%$ \\
Italy & 1 & $2 \%$ \\
\hline Total & 63 & $100 \%$ \\
\hline
\end{tabular}

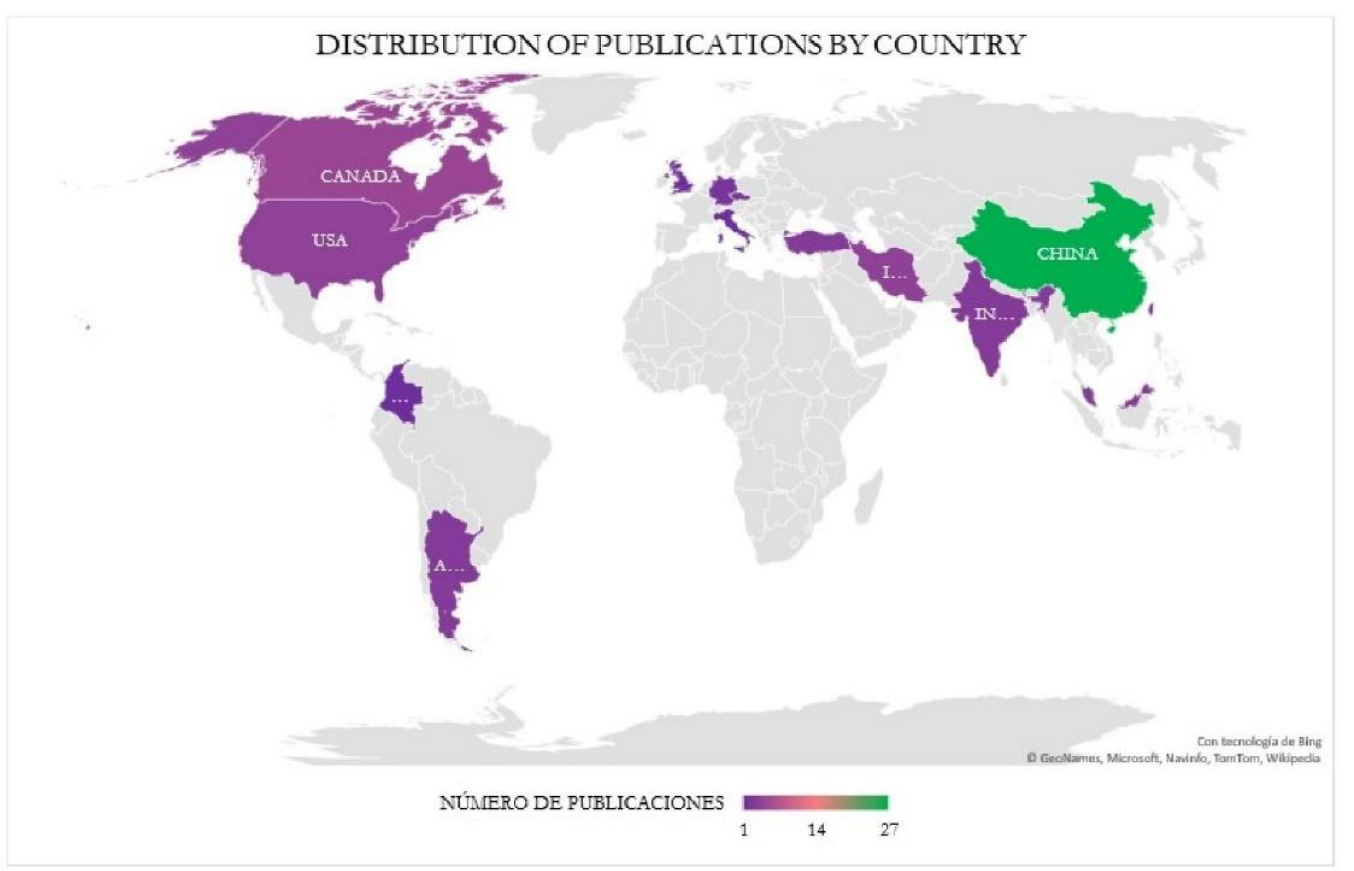

Figure 3. Distribution of publications by country.

As visualized, it can be noted that, by continent, $70 \%$ of publications are located on the Asian continent, the second value is in North America with $14 \%$ of publications, Europe takes the third place in this ranking with $10 \%$ and ultimately ranks is South America with $6 \%$. It should be noted that no publications were located in Central America or Africa, or Oceania.

\subsection{Background Data}

3.2.1. Problem/Type of Production Process Studied

The problems or types of production processes found in the analyzed papers are:

Flexible process: Refers to the opportunity to produce the same part with different sets of operations, such as in workshops and flexible machining cells [17]. 
Flow Shop: $\mathrm{N}$ jobs are processed in $\mathrm{m}$ machines with the same sequence, and a job cannot be delivered before all processing ends on the current machine [18] for use in industries such as textiles, plastics, chemical, semiconductor, tiles, and many others [19].

Hybrid or Flexible Flow Shop: Commonly, there are several stages with parallel machines that may not be the same. Each work must flow through each of the previous stages according to the same sequence, the performance of the system is given by the performance of each work at each stage [20], cases presented in industries such as glass, steel, plastic, and pharmaceutical. Its main feature is that the job is not allowed to move to the next stage until the process is completed, which leads to the machine timeout [21].

Job Shop: Each job follows a default path on $\mathrm{m}$ machines. There is a differentiation between job shops in which each job visits each maximum machine once and job shops in which a job can visit each machine more times [22].

Flexible Job Shop: Generalization of the job shop and parallel machine environments. There are c work centers, and in each work center, there are several identical machines in parallel. Each job has its path to follow, so it requires processing at each work center on a single machine, and any machine can do so [22].

Other: Other types of structures of production processes are recognized but differ from the classes indicated above.

Table 5 lists the papers grouped into these categories, while Figure 4 shows the weight of each type on all the publications analyzed.

Table 5. Papers grouped according to the type of Productive Process.

\begin{tabular}{cc}
\hline Process & Papers \\
\hline Flow Shop & {$[18,19,21-56]$} \\
\hline Hybrid or Flexible Flow Shop & {$[20,57-68]$} \\
\hline Job Shop & {$[69-73]$} \\
\hline Flexible Job Shop & {$[74-78]$} \\
\hline Other & {$[17,79,80]$} \\
\hline
\end{tabular}

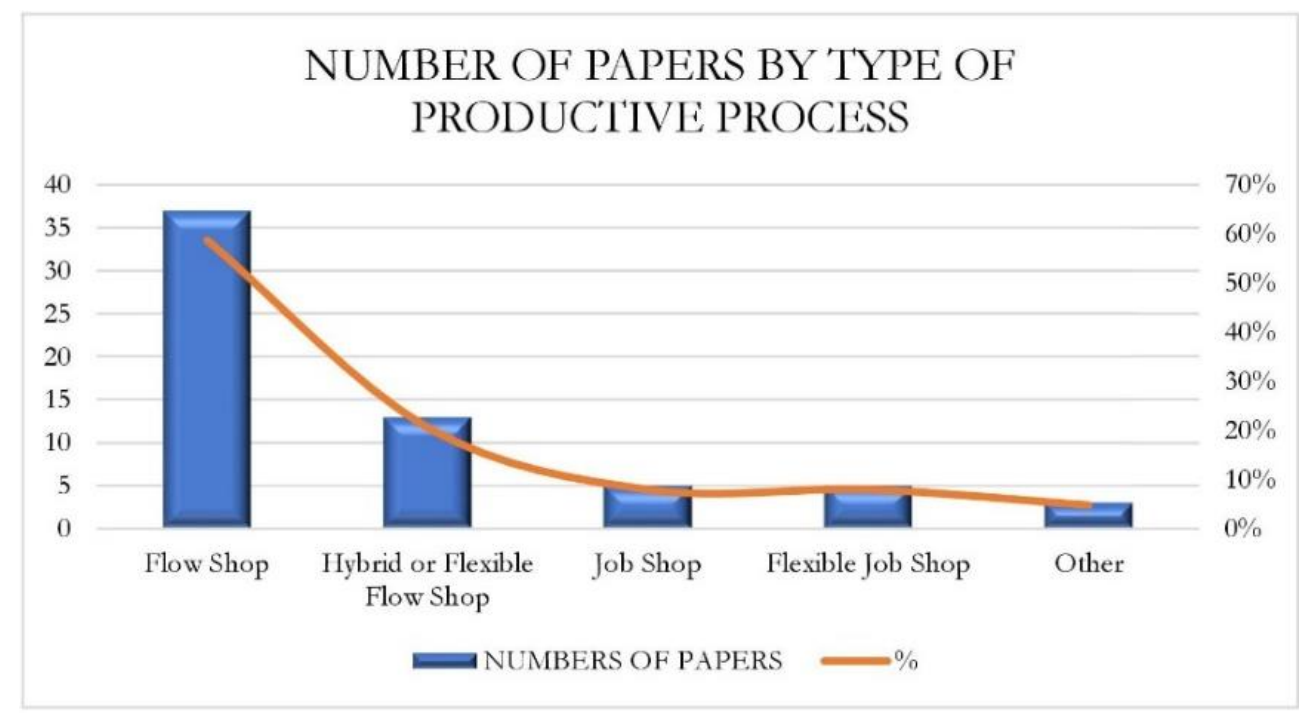

Figure 4. Number of papers depending on the type of production process.

\subsubsection{Additional Features and Times Considered}

In addition to the basic features of the problem analyzed, other further features or additional times are mentioned, which are restrictions on the formulation of the principal problem and are not necessarily mutually exclusive. Among those that are indicated: 
Transport activities: For the transfer or handling of lots, with a limited capacity, as in the case of $[39,71]$.

Blocking: Programming problems that do not consider intermediate buffers between adjacent machines and the first machine is inactive until the next machine can process the work, restriction proposed by [23-26,28,43].

Learning effect: Processing time decreases as operator experience increases; this is indicated in investigations of [41,45].

Preventive maintenance: Machines are not available all the time and are performed for a predefined time, present in the studies of [23,49-51].

\subsubsection{Configuration/Work Number-Machines}

Although nomenclatures are not always the same, the configurations can be subdivided into two:

Generic: Where, once the calculation of the solution was developed, it can "play" with the number of jobs, machines, and stages, the authors who have indicated these configurations are displayed in Table 6 . A total of $81 \%$ of the investigated papers belonged to this group.

Table 6. Papers according to configuration/work number-generic machines.

\begin{tabular}{|c|c|c|}
\hline Configuration & Number of Papers & $\%$ \\
\hline $\begin{array}{c}\text { j jobs } \\
\mathrm{m} \text { machines }\end{array}$ & 35 & $55 \%$ \\
\hline $\begin{array}{c}\text { j jobs } \\
\text { m parallel machines } \\
\text { s stages }\end{array}$ & 7 & $11 \%$ \\
\hline $\begin{array}{c}\text { j jobs } \\
\text { m machines } \\
\text { s stages }\end{array}$ & 2 & $3 \%$ \\
\hline $\begin{array}{c}\text { j jobs } \\
\text { m non-identical machines }\end{array}$ & 2 & $3 \%$ \\
\hline $\begin{array}{c}\text { j jobs } \\
\text { m identical parallel machines } \\
\text { s stages }\end{array}$ & 2 & $3 \%$ \\
\hline $\begin{array}{c}\text { j jobs } \\
\text { m non-identical machines }\end{array}$ & 2 & $3 \%$ \\
\hline $\begin{array}{c}\text { j jobs } \\
\text { m heterogenous machines }\end{array}$ & 1 & $2 \%$ \\
\hline $\begin{array}{c}\text { j jobs } \\
\text { m series machines }\end{array}$ & 1 & $2 \%$ \\
\hline Total & 52 & $81 \%$ \\
\hline
\end{tabular}

Specific: Where the problem's solution was developed in a particular number of jobs, machines, and stages, the authors have pointed out the configurations indicated in Table 7. A total of $19 \%$ of the investigated papers belonged to this group. 
Table 7. Papers according to configuration/work number-specific machines.

\begin{tabular}{|c|c|c|}
\hline Configuration & Number of Papers & $\%$ \\
\hline $\begin{array}{c}\text { j jobs } \\
2 \text { machines }\end{array}$ & 3 & $5 \%$ \\
\hline $\begin{array}{c}1 \text { job } \\
\text { m machine }\end{array}$ & 1 & $2 \%$ \\
\hline $\begin{array}{l}1 \text { jobs on machine } 1 \\
\text { j jobs on machine } 2 \\
2 \text { machines }\end{array}$ & 1 & $2 \%$ \\
\hline $\begin{array}{c}1 \text { machine at Stage } 1 \\
2 \text { identical parallel machines at Stage } 2 \\
2 \text { stages }\end{array}$ & 1 & $2 \%$ \\
\hline $\begin{array}{l}2 \text { parallel machines } \\
2 \text { stage }\end{array}$ & 1 & $2 \%$ \\
\hline $\begin{array}{c}3 \text { jobs } \\
1 \text { machine on Stage } 1 \\
2 \text { machines on Stage } 3 \\
3 \text { stages }\end{array}$ & 1 & $2 \%$ \\
\hline $\begin{array}{l}\text { j jobs } \\
\text { m parallel machines on Stage } 1 \\
\mathrm{n} \text { parallel machines on Stage } 2 \\
2 \text { stages }\end{array}$ & 1 & $2 \%$ \\
\hline $\begin{array}{l}\text { j jobs } \\
1 \text { machine } \\
\text { s stages }\end{array}$ & 1 & $2 \%$ \\
\hline $\begin{array}{l}\text { jjobs } \\
\text { m machines } \\
3 \text { stages }\end{array}$ & 1 & $2 \%$ \\
\hline $\begin{array}{l}\text { j jobs } \\
2 \text { machines } \\
2 \text { stages }\end{array}$ & 1 & $2 \%$ \\
\hline Total & $52^{1}$ & $81 \%$ \\
\hline
\end{tabular}

${ }^{1}$ The sum of papers of the two types is 64 because one paper analyzes cases belonging to the two types.

\subsubsection{Types of Sublots or Jobs}

Sublots are the partitioning of the transfer batch into smaller batches, appropriate for minimizing the target function. Three types of sublots are identified as described in [6]:

Consistent: If the lot size is the same for each pair of machines, with this type of batches work $[17,21,34,38,41,42,48-51,57,59,61,64,67-69,75]$.

Variables: If the lot size varies on all machines, this type of lot is found in work performed by $[20,32,39,40,47,49,54,58,63,66,78]$.

Equal: If all sublots along all machines are the same size, $[18,19,23-31,33,35-37,43-$ $46,48,49,52,53,56,60,62,65,66,70-72,74,76,77,79,80]$, investigate this type of sublot.

The proportionality of the number of publications per sublot is shown in Figure 5.

\subsubsection{Idling}

It is considered as a restriction when designing the models that will solve the problems formulated, being able to understand various types, such as idling between adjacent sublots, but on the same machine or in one or more stages, in the exchange of jobs, or when there are no pending jobs.

Of the papers analyzed, only $26(41 \%)$ report that they consider this a restriction; in turn, of these publications, $6(10 \%)$ check the utility of Lot Streaming under idling conditions against non-idling conditions. 


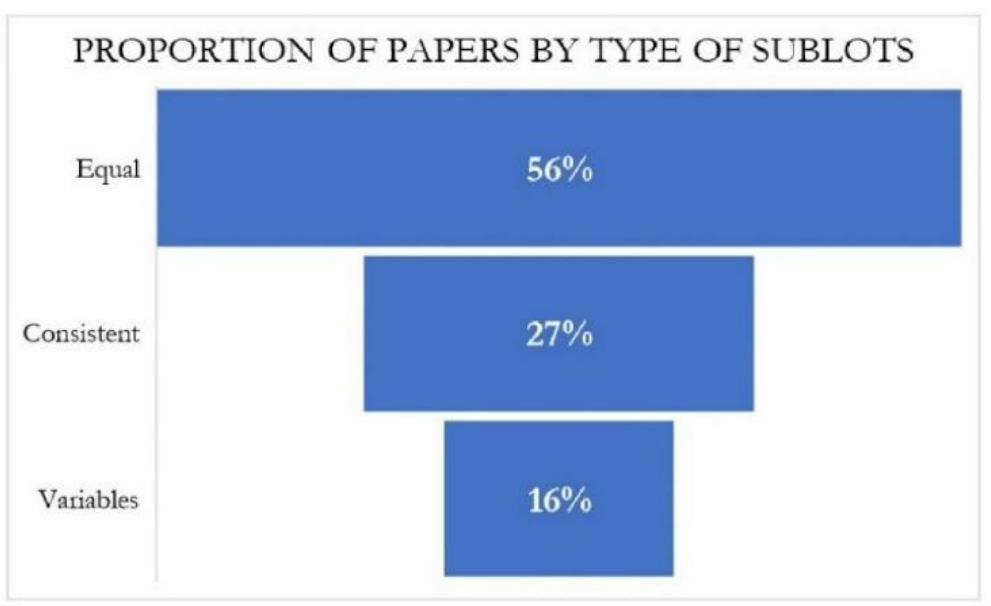

Figure 5. Percentage of papers depending on the type of sublot.

\subsubsection{Buffer}

This additional inventory strategically placed to avoid disruptions to operations [1] is a new constraint to consider. Eleven publications $(17 \%)$ report that buffers are taken into account, of which only $1(2 \%)$ is of limited capacity; the others are described as unlimited or infinite capacity.

\subsubsection{Setup Time}

It is the time to prepare a machine or process for the next production order [1]; this would be another restriction for developing the optimization problem solution.

$86 \%$ (54) of the revised publications mention in some way the existence of a setup time; however, of these, 18 papers (29\%) indicate that setup time is negligible or already included in the processing time. In 18 papers $(29 \%)$, setup time depends on the sequence that jobs have on different machines, 16 papers $(25 \%)$ point out that their setup time restriction has a sequence-independent configuration; finally, two papers (3\%) make a comparison in the Lot Streaming with and without setup time.

\subsubsection{Objectives}

As noted, the goal of Lot Streaming is to minimize Makespan; 55 of the revised papers $(87 \%)$ point to this as the main objective to be achieved, being able to express it in other words. Subsequently, the following objectives sought to meet are to minimize precocity and tardiness times, defined as the difference between actual end times and the date at which it was scheduled [24]; although there are other objectives, they are a minority.

\subsubsection{Calculating the Problem Solution}

According to the different demonstrations and studies, the problem we are referring to is the NP-Hard type [58]. Under this definition, different schemes were developed to suggest a solution to the proposed problem; taking into account the characteristics of machines, sublots, and the restrictions determined by each configuration; two significant subgroups are generated:

Optimization algorithm: These can be generic algorithms generated according to the problem to be solved. These have already been developed and tested by an author and coupled to the type of problem to be solved. The papers that propose this type of solution are indicated in Table 8, with 47 publications or $75 \%$. 
Table 8. Papers that propose an algorithm to calculate the solution.

\begin{tabular}{|c|c|}
\hline Algorithm & Papers \\
\hline HA: Heuristic algorithm & {$[62,63,68]$} \\
\hline HGA: Hybrid genetic algorithm & {$[46,47,54]$} \\
\hline SA: Simulated annealing & {$[40,57,66]$} \\
\hline DABC: Discrete artificial bee colony & {$[37,44]$} \\
\hline DPA: Dynamic programming algorithms & {$[21,55]$} \\
\hline DSOMA: Discrete self-organizing migrating algorithm & {$[31,52]$} \\
\hline GA: Genetic algorithm & {$[61,64]$} \\
\hline IMMBO: Improved migrating birds optimization & {$[18,60]$} \\
\hline $\begin{array}{l}\text { DEA: Differential Evolution Algorithm/PSO: Particle Swarm } \\
\text { Optimization }\end{array}$ & [29] \\
\hline GLASS-POTTS/JOHNSON'S & [48] \\
\hline ABC: Artificial bee colony & [72] \\
\hline DACS: Distributed ant colony system & [76] \\
\hline DIWO: Discrete invasive weed optimization & [19] \\
\hline DLHS: Local-best harmony search with dynamic sub-harmony memories & [35] \\
\hline DPSO: Discrete particle swarm optimization & [53] \\
\hline EDA: Estimation of distribution algorithm & [30] \\
\hline EMMBO: Effective modified migrating birds optimization (EMBO) & [65] \\
\hline GAJS: Genetic algorithm-based job splitting approach & [73] \\
\hline GEA: Greedy constructive algorithm & [74] \\
\hline HDABC: Hybrid discrete artificial bee colony & [24] \\
\hline HDHS: Hybrid discrete harmony search & [56] \\
\hline ILS: Iterated local search & [33] \\
\hline INSGA-II: Improved Non-dominated Sorting Genetic Algorithm II & [27] \\
\hline MA: Memetic algorithm & [77] \\
\hline MABC: Modified artificial bee colony & [69] \\
\hline MHA: Metaheuristic algorithm & [45] \\
\hline MOMBO: Multi-Objective Migrating Birds Optimization & [25] \\
\hline NEMO: Novel evolutionary multi-objective optimization & [26] \\
\hline NGA: New genetic algorithm & [28] \\
\hline NSGA II: Non-dominated Sorting Genetic Algorithm II & [58] \\
\hline $\begin{array}{l}\text { ONSGA-II: Optimization Improved Non-Dominated Sorting Genetic } \\
\text { Algorithm }\end{array}$ & [43] \\
\hline PA: Polynomial-time algorithm & [41] \\
\hline $\begin{array}{l}\text { PH-MOEAD: Problem-specific heuristics multi-objective evolutionary } \\
\text { algorithm based on decomposition. }\end{array}$ & {$[20]$} \\
\hline REMO: Evolutionary multiobjective robust scheduling & [23] \\
\hline SFLA: Shuffled frog leaping algorithm & [36] \\
\hline TF-HI algorithm & [59] \\
\hline
\end{tabular}

Other calculation schemes: Other formulations do not indicate belonging to a specific algorithm. The publications that propose this type of solution are detailed in Table 9, with 16 papers or $25 \%$. 
Table 9. Papers that propose other schemes to calculate the solution.

\begin{tabular}{cc} 
Algorithm & Papers \\
\hline MILMM: Mixed-integer linear mathematical model & {$[32,42,49-51]$} \\
\hline Mathematical model & {$[38,67,79,80]$} \\
\hline MILP: Mixed-integer linear programming & {$[71,78]$} \\
\hline Existing convex programming techniques & {$[34]$} \\
\hline CP: Constraint Programming & {$[75]$} \\
\hline TSM: Three-stage method & {$[39]$} \\
\hline $\begin{array}{c}\text { DSS: Integrated decision support system that combines } \\
\text { multicriteria/AHP simulation and decision-making approaches: }\end{array}$ & {$[70]$} \\
\hline IMalytical Hierarchy Process/WAM: Weighted Aggregation Method & {$[17]$} \\
\hline
\end{tabular}

\subsubsection{Software for Solving the Problem}

To solve the problem and verify that the objective is appropriate, programming software or statistical analysis was used. The percentage of use of each software is indicated in Figure 6; 16\% of the publications do not indicate the program to test their solution. Additionally, the software was grouped according to its base; for example, $\mathrm{C}++$ is a general name that includes Visual $\mathrm{C}++, \mathrm{C}++$, or $\mathrm{C}$.

\section{SOFTWARE FOR CALCULATE THE SOLUTION}

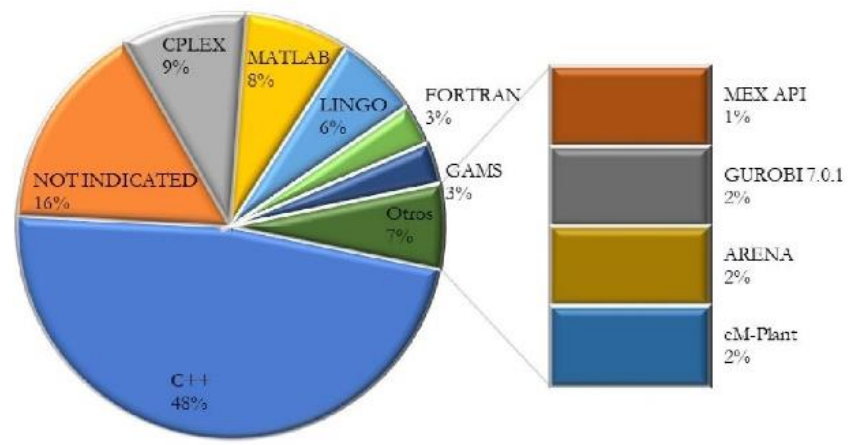

Figure 6. Software used to solve the problem.

As can be seen in Figure 6, software such as IBM ILOG Cplex Optimizer V12.8 and Lingo 18.0 by Lindo Systems Inc(Chicago, IL, USA) were used to calculate the solution called "other calculation schemes" (as indicated in the previous characterization), or classical mathematical programming, that is, variants of linear programming, as indicated by Sun [81] and validated by Anand et al. In contrast, programming software (C++, Fortran) was used to program-specific algorithms previously tested due to their ability to solve and the more effective assignment of operational restrictions, pointed out by Kovács in his study [82].

\subsubsection{Compared to}

A total of $95 \%$ of the papers compare the proposed scheme to solve the problem with another scheme, another algorithm, or the same algorithm with other conditions. Table 10 shows how each author has compared his proposed solution against another previously demonstrated solution(s) in the papers that propose an algorithm as a calculation scheme, while Table 11 does so for other schemes. 
Table 10. Comparisons for algorithms proposed to calculate the solution.

\begin{tabular}{|c|c|}
\hline Algorithm & Compared to \\
\hline HA: Heuristic algorithm & $\begin{array}{l}\text { The same TSAS-MP-MIP/TSAS-CP-MIP issue resolved in } \\
\text { Solver, RK: Random Key Method/WSPT: Weighted Shortest } \\
\text { Processing Time/JR: Johnson's Rule, and the same issue } \\
\text { resolved in LINGO 11.0 with a Brauch and Bound algorithm }\end{array}$ \\
\hline HGA: Hybrid genetic algorithm & $\begin{array}{l}\text { GA, the same problem solved in Cplex, and the same problem } \\
\text { but comparing the use of Variable Sublots and Consistent } \\
\text { Sublots }\end{array}$ \\
\hline SA: Simulated annealing & $\begin{array}{l}\text { The same problem solved in Lingo, GA, Baker, the same } \\
\text { problem solved in Cplex, and the performance of the parallel SA } \\
\text { is evaluated against a sequential SA }\end{array}$ \\
\hline DABC: Discrete artificial bee colony & HGA, HDPSO, SA, TA, ACO y DPSO \\
\hline DPA: Dynamic programming algorithms & $\begin{array}{l}\text { Proposal by Bukchin et al. (2002) and the same algorithm with } \\
\text { different working values }\end{array}$ \\
\hline DSOMA: Discrete self-organizing migrating algorithm & $\begin{array}{l}\text { The same algorithm using the venerable Mersenne } \\
\text { Twister, and the same but generic algorithm }\end{array}$ \\
\hline GA: Genetic algorithm & $\begin{array}{l}\text { The same algorithm executed on both sequential and parallel } \\
\text { computing platforms (using the PGA island model), SA and } \\
\text { MILP solved in Lingo }\end{array}$ \\
\hline IMMBO: Improved migrating birds optimization & $\begin{array}{l}\text { TLGA, iFOA, DIWO, DE-ABC, EMBO, MBO, EGA, DIWO Y } \\
\text { ABC }\end{array}$ \\
\hline $\begin{array}{l}\text { DEA: Differential Evolution Algorithm/PSO: Particle Swarm } \\
\text { Optimization }\end{array}$ & TEA y ACO \\
\hline \multicolumn{2}{|l|}{ GLASS-POTTS/JOHNSON'S } \\
\hline ABC: Artificial bee colony & GA y TS \\
\hline DACS: Distributed ant colony system & $\mathrm{PSO}$ and $\mathrm{CP}$ \\
\hline DIWO: Discrete invasive weed optimization & EDA, ISFH, and ABC \\
\hline $\begin{array}{l}\text { DLHS: Local-best harmony search with dynamic sub-harmony } \\
\text { memories }\end{array}$ & HGA y HDPSO \\
\hline DPSO: Discrete particle swarm optimization & GA, GOOD, ACO y TA \\
\hline EDA: Estimation of distribution algorithm & $\begin{array}{c}\text { EDA (and variants), DABC, ACO, DPSO, HGA, SA (and } \\
\text { variants), TA (and variants), and TS }\end{array}$ \\
\hline $\begin{array}{l}\text { EMMBO: Effective modified migrating birds optimization } \\
\text { (EMBO) }\end{array}$ & MBO, IMBO, MMBO, GA, GAR, DPSO y DABC \\
\hline GAJS: Genetic algorithm-based job splitting approach & $\begin{array}{l}\text { Fixed Number Work Division Approach (FNJS), taking into } \\
\text { account different dispatch rules }\end{array}$ \\
\hline GEA: Greedy constructive algorithm & $\begin{array}{l}\text { CPO, MILP-CN /MILP-MM solved with Solver and the same } \\
\text { problem with and without Lot Streaming }\end{array}$ \\
\hline HDABC: Hybrid discrete artificial bee colony & TA, INSGA, NGA y BBEDA \\
\hline HDHS: Hybrid discrete harmony search & DPSO \\
\hline ILS: Iterated local search & HGA, DPSO y DLHS \\
\hline $\begin{array}{l}\text { INSGA-II: Improved Non-dominated Sorting Genetic } \\
\text { Algorithm II }\end{array}$ & DHS, TA, basic NSGA-II \\
\hline MA: Memetic algorithm & The same algorithm allowing or not to preemption \\
\hline MABC: Modified artificial bee colony & GA, OPGA y TS \\
\hline MHA: Metaheuristic algorithm & SA y TS \\
\hline
\end{tabular}


Table 10. Cont.

\begin{tabular}{cc}
\hline Algorithm & Compared to \\
\hline MOMBO: Multi-Objective Migrating Birds Optimization & BASIC MBO, h-MOEA, m-MOEA/D y REMO \\
\hline NEMO: Novel evolutionary multi-objective optimization & INSGA-II and PBEDA \\
\hline NGA: New genetic algorithm & GA \\
\hline NSGA II: Non-dominated Sorting Genetic Algorithm II & i-AWGA, SPEA2 \\
\hline $\begin{array}{c}\text { ONSGA-II: Optimization Improved Non-Dominated Sorting } \\
\text { Genetic Algorithm }\end{array}$ & DHS, NSGA-II, and TA \\
\hline $\begin{array}{c}\text { PA: Polynomial-time algorithm } \\
\text { evolutionary algorithm based on decomposition. }\end{array}$ & EMBO, GA, GAR, DPSO y DABC \\
\hline REMO: Evolutionary multiobjective robust scheduling & INSGA-II, PBEDA, MMSA, MOMA \\
\hline SFLA: Shuffled frog leaping algorithm & HGA, TA y ACO \\
\hline TF-HI algorithm & TF-I y TSHF-LSP
\end{tabular}

Table 11. Comparisons for other schemes proposed to calculate the solution.

\begin{tabular}{cc}
\hline Solution & Compared to \\
\hline MILMM: Mixed-integer linear mathematical model & $\begin{array}{c}\text { The same problem with and without Lot Streaming and using } \\
\text { various conditions and constraints (lot size, intermingling, } \\
\text { maintenance times, sublot types) }\end{array}$ \\
\hline Mathematical model & $\begin{array}{c}\text { The same problem solved in Cplex, using different sublot sizes } \\
\text { and transfer types and pure Flowshop against Hybrid Flowshop }\end{array}$ \\
\hline MILP: Mixed-integer linear programming & $\begin{array}{c}\text { The same problem with and without Lot Streaming using } \\
\text { various conditions and restrictions }\end{array}$ \\
\hline Existing convex programming techniques & The same problem with and without Lot Streaming using \\
various conditions and restrictions \\
CP: Constraint Programming
\end{tabular}

DSS: Integrated decision support system that combines

multicriteria/AHP simulation and decision-making approaches:

Analytical Hierarchy Process/WAM: Weighted

Use of different dispatch rules

Aggregation Method

\subsubsection{Metrics to Evaluate}

After proposing the problem-solving scheme, a comparison with another type of solution was proposed, and different tests are carried out to demonstrate the proposed solution's effectiveness. Among the main comparison arguments are:

- The objective function and the maximum, minimum, and standard deviations.

- Central Pocessing Unit (Cpu) Time.

- $\quad$ AverageRetail Price Index (Rpi) Value.

- Hypervolume, Convergence.

- $\quad$ Statistical tests such as Analysis of Variance (ANOVA), Mood Median Test, MannWhitney Test, Student's T-Test, Mann-Whitney U-Test. 


\subsection{Final Data}

\subsubsection{Conclusion}

The analyzed papers propose the use of a specific calculation algorithm or method as a solution to the specific Makespan reduction problem. To demonstrate that the solution method is effective, comparisons with other forms of a solution were considered, very well documented in previous studies, for which different criteria or metrics are applied. It is important, as an investigative value, to mention the use of Applied Statistics to research because it allows generating an analysis focused on determining the proposals that produce the best results, once the objective function was raised. This type of analysis joins the work time of the CPU as the maximum types of metrics valued within the analysis of the results of each paper.

After comparing the results obtained in the numerical demonstrations of the proposed models, each author concludes that the proposed algorithm is effective to reduce the Makespan through the use of Lot Streaming. This conclusion is based on obtaining better numbers in the metrics reviewed in several algorithms that use the same mathematical model to reach the same resolution, that is, the conclusion is reached by comparing results with the same initial parameters. It should be noted that in none of the articles reviewed is there a conclusion that analyzes the basic definition of Lot Streaming since it has already been analyzed by other authors in previous years, so this demonstration is implicit.

The experimental results that each author achieves justify the importance of generating new developments, to continue developing and corroborating the suitability of new algorithms or calculation software. Thus, achieving better competitive performances and solving the problem are considered effective, generating new alternatives for the improvement of production management.

\subsubsection{Future Works}

Fifty-one publications (that is, $81 \%$ ) propose future research based on the results of the analyzed article. Mathematical model validations are proposed taking into account specific working conditions or more realistic problems on the different production processes and dynamic characteristics, reducing computational complexity, proposing different restrictions or uncertainties.

Alternatively, it is proposed to work on the definition of new objectives or convert single-objective algorithms into multi-objectives, using self-adaptive algorithms focused on self-learning, or extend the proposed algorithm to a heuristic or metaheuristic algorithm to achieve a more intuitive and iterative result that achieves a larger universe. In other words, most researchers intend to carry out even more research, showing that the subject analyzed is important to improve working conditions in industries and reduce costs related to productivity.

To carry out this future research, the authors formalize the need to investigate new manufacturing systems, such as non-conventional ones, such as those based on cellular or fractal designs, where research is quite limited. In this way, we can appreciate that there is always something more to investigate since the Theory of Production and Operations Management is not static, but rather dynamic, therefore more explicit modeling of an industrial productive reality can always be found.

\section{Discussion}

\subsection{Research Questions}

After making the investigation, it is possible to answer the questions proposed in Table 1.

QR1. In what types of production processes has LS been applied?

This is the central data to be analyzed in the present systematic review, as it allows to recognize the applicability of the Opportunity for Improvement that is the LS concerning the industrial environments. 
In the analyzed papers, the two main reported types of processes are the Flow Shop, as the most studied process, both in its pure scheme or hybrid at 79\% (50 of 63 papers), which would indicate at a glance that it is the most repetitive process at the industrial level. The Job Shop (both pure and hybrid) has only 16\% (10) of publications.

It can add different restrictions or particular characteristics in the two types, so that the designed model is more attached to the day-to-day living industries, pointing as main restrictions the transport, blocking maintenance, or effect of the so-called learning curve.

By answering this research question, we can infer that the LS can be extended to any production process once it is recognized its type and thus can generate a model according to the reality of the industry that is looking to optimize.

QR2. For what types of sublots is LS used?

To formulate the problem to be solved, it is necessary to recognize different characteristics of the model to be developed initially; among them, the type of sublot has a critical weight. In this analysis, most papers provide solutions for schematics with equal sublots, i.e., more than half of the papers (56\%), while $27 \%$ generate solutions with consistent sublots and $16 \%$ with variable sublots.

Additionally, several of the revised papers mention different special considerations, such as idle times; however, only $41 \%$ mention their existence, or the case of buffers, in which only $17 \%$ talk about the presence of interprocess security inventories, the most mentioned aspect being preparation times, which $86 \%$ of the items take into account.

QR3. What optimization algorithms have been used for LS calculation?

The calculation of the solution for the proposed problem is the objective function of an optimization algorithm (widely mentioned in the literature) in 47 of the reviewed publications. The algorithms HA: Heuristic algorithm, HGA: Hybrid genetic algorithm, and SA: Simulated annealing are highlighted, which are mentioned several times in the review.

For their part, 16 publications do not indicate the use of an algorithm, but instead use other solution schemes, such as a mathematical formulation with some variant to get a coupling with the sketch initially lifted.

The solutions were parameterized in different programming software, such as $\mathrm{C}++$ with $48 \%$, or statistical optimization programs, such as CPLEX with 10\%, demonstrating in 60 of the publications when comparing with other forms of calculation that the solution proposed in each paper is optimal thanks to specific metrics applied to the objective function statistically. In this way, it is concluded that an improvement in production processes and implicit costs can be achieved, but there will always be a new way to continue improving, such as a new generation of algorithms.

\section{QR4. Has LS been used to decrease Makespan?}

Among the revised papers, several optimization objectives are mentioned, such as energy consumption and costs associated with production processes; however, most papers $(73 \%)$ explicitly mention that the objective minimization function corresponds to Makespan (or associated words), thus becomes clear the fact that this is the best utility of Lot Streaming (LS).

Therefore, it can be concluding that applying this optimization technique would result in an improvement in the delivery times of the final product, which would generate customer satisfaction, because it can see its needs fulfilled, in addition to the company avoiding having lost sales, which is a conflict that companies have to face and makes them lose customers.

\subsection{Comparison of Current Work with Existing Work}

As a result of the search for publications in indexed journals referring to literature reviews on Lot Streaming (maintaining the search strategy of the present work), four articles were found, the first of these (in order of publication) is the one presented by Bagchi et al. in 2006 [11]. This paper proposes a review of applications of blocking programming models in robotic cells modeled with TSP (traveling salesman problems) but oriented only to a Flow Shop environment. Hence, it is not an open investigation such as the present one, 
which investigates the different approaches to programming problems that can be solved with LS and the different production processes.

The following article is presented by Chang et al. in 2007 [9], where a complete review of LS is carried out, in which the evolution of LS research is outlined; that is, the research was not blinded to a current period. This work proposes a structure of dimensions, subdimensions, and levels that allow maintaining a more centered skeleton; however, it does not contrast the optimization algorithms that allow calculating and solving programming problems using the LS.

Gómez-Gasquet et al. presented the third article in 2013 [10], where an investigation about the state of the art of LS is also carried out in a Flow Shop. That means that it does not consider other types of production processes such as the Job Shop or the Open Shop (of which definitively no references were found). However, in his references, he does not discriminate the age of the publications, finding articles published in 1989, also if he presents a graph that refers to the techniques to solve the problem described, where the types of algorithms used, but does not indicate what they are, and this, according to the authors, is an essential aspect for future research.

Finally, Cheng et al. [8], also in 2013, proposed a review of the practically theoretical literature about LS in a scheme based on the objective of the application, that is, based on cost or based on time. In this paper, the different aspects, restrictions, and considerations for the mathematical model approach to be solved are raised, and a description of the solutions used, with references to publications in 1975, in a very sober way. This publication is a reasonable frame of reference to carry out this research.

Based on the articles mentioned, the present research provides a better source of study because it considers all the production processes in which LS was applied; that is, it does not focus on any specific one. Additionally, due to having followed the guidelines of the PRISMA methodology, the systematic review is managed in a better way because it avoids redundancy in the information and bias towards a particular criterion.

Considering only research from indexed publications also allows generating a more austerity scheme to researchers to ensure that the sources cited in this paper were the best by the methodological quality of the information contained in each document.

In addition, more factors were analyzed apart from the background ones, so that they constitute different aspects that could be analyzed and be a source of new specific research, for example, the country is published, which defines that in specific continents such as Africa it is not have reported research on LS. Based on this information, analysis, or implementation focused on the industry in this country could be carried out.

It is considered that the segmentation of the information sources after ten years of publication, while the four papers found on LS cite references with many more years of antiquity, does not limit the publication in terms of conceptual references. The reviewed research cites references that, in turn, are based on these ancient investigations, which ultimately proposes a frame of reference with solid and well-documented bases.

\subsection{Contributions to Literature}

The work developed presents a compendium of relevant information found in $63 \mathrm{sci}-$ entific articles on Lot Streaming, adding descriptive graphics so that the results obtained are visually contrasted at a glance. The summary tables allow detailing the scope of the consulted sources in a structured scheme. In addition, a scale of the analyzed information is carried out to cover with better specificity the data that constitute a literature review.

Having raised several research questions from the start has allowed the research to be guided in a way that focuses on the aspects considered to be central within the systematic review carried out, that is, the types of production processes, the types of batches with which they work, the algorithms to calculate the solution, and the objective of applying LS in an industry. With this strategy, the transcendental is demonstrated; therefore, the research is presented as valid in specific topics of LS. 
In addition, considering that the limitation of the publication years (10 years), more modern and fresh research is proposed, based on the evolution of optimization algorithms since every day it is proposed more intelligent and developed. In addition to specific software and statistical programs, to solve programming problems in a more orderly way, but also showing the different limitations or gaps that must be covered to make the calculation more precise, mainly considering that recent publications refer to previous research has since been evaluated as of the necessary quality to nurture a proposed work.

\subsection{Implications for Practice}

For future practical research, it can be made from the production processes applying LS. The new investigation will identify the need to optimize the production processes and validate that this is a tool according to the requirements. Next, they will be pigeonholed within these types of processes, the types of batches used, and the configuration of jobs, machines, and stages to adequately model the problem to be solved. Finally, select the algorithms with which one works, or propose a new algorithm or mathematical formulation to solve the specific programming problem.

\subsection{Limitations}

This review has several limitations, the first one refers to the initial knowledge (that is when defining the research topic) on the subject of batch partitioning of the amount of production to be obtained in a given time. However, while the research was being carried out, the spectrum of knowledge was opened, so that more structured analysis objectives could have been identified and with greater weight within the world of research, with a broader knowledge of Lot Streaming.

The following limitation refers to biased the analyzed information to consulted scientific databases which have DOI (Digital Object Identifier), it was also considered as an information validator (to eliminate papers duplicates). However, if another qualification of the databases or the reviewed journals had been taken into account, the bias of the information would have been avoided and other documents of good value could have been considered within the research.

An additional limitation is constituted by a lack of information about the production axis of the industries where the Lot Streaming could have been applied about the reduction of the Makespan, that is, if it could be applied in the same way in the food industry as in the footwear industry, since this was the initial objective when raising the issue to be demonstrated. When observing that these definitions are not popular in the reviewed articles, the general objective was modified to review the types of production processes where the LS was applied, since in this way it is proposed in the future to infer whether, when analyzing the production process that follows an industry, this allows to conclude the use of this methodology, regardless of the product that it produces.

\section{Conclusions and Future Works}

The systematic review through the PRISMA methodology has shown that the use of Lot Streaming is helpful to reduce the Makespan, in addition to allowing the ability to achieve other objectives, such as the reduction of operating costs (maintenance, inventory management, electricity), which lead to the correct Productivity Management, resulting in improving the profitability margin of industries.

One of the strategies to achieve operational excellence in the industry is the adoption of Continuous Improvement tools. Lot Streaming allows for being framed in this philosophy, taking into account that it makes use, according to the publications analyzed, of different Optimization Algorithms. These are of maximum use for the mathematical modeling of the problem to be analyzed (the operational reality of the industry) and they can capture different scenarios aimed at an increase in production with the minor use of resources (human, material, time). 
The evolution of technology leverages the development of the industry because the development of new alternatives for organization, administration, control, improvement for industrial management is essential due to the emergence of new software and hardware with better benefits, which are not constituted in a kind of limitation for the execution of the applications that are required in different business uses.

The analytical review of papers allowed us to recognize that this technique is positively used in various types of production processes, so it can be extended to a lot of industries, with their specific characteristics, thus, it is proposed to review the use of Lot Streaming in different industrial production approaches. Then, based on the primary analysis of the operational characteristics of the production processes and the formulation of different types of fundamental uncertainties that in turn become programming constraints, formulate mathematical modeling according to the most appropriate algorithm (which includes comparing the operation of the different algorithms, as was carried out in most of the reviewed studies). Consequently, calculating the optimized Makespan, comparing the application of this technique in different industrial axes, to show the differences or difficulties presented.

Another issue to be validated for future research and applications is the use of other methods of modeling, optimization, and comparison of the improvements made to production processes. The premise to maintain is to reduce the use of resources and improve productivity without altering the application of the concepts of the flexibility of resources, product families, and innovation of the processes and the operational staff's knowledge.

Author Contributions: A.S.-M. conducted the literature search (all the phases of the study selection procedure), performed the quality assessment of primary studies, interpreted the results, and wrote the manuscript. M.V.G. guided the writing of the manuscript and was involved in finalizing it. All authors have read and agreed to the published version of the manuscript.

Funding: This work was supported by the Universidad Tecnica de Ambato (UTA) and their Research and Development Department (DIDE) under project CONIN-P-256-2019, and SENESCYT by grants "Convocatoria Abierta 2011" and "Convocatoria Abierta 2013".

Institutional Review Board Statement: Not applicable.

Informed Consent Statement: Not applicable.

Conflicts of Interest: The authors declare no conflict of interest.

\section{References}

1. Hill, A.V. The Encyclopedia of Operations Management: A Field Manual and Glossary of Operations Management Terms and Concepts; FT Press: Upper Saddle River, NJ, USA, 2012; ISBN 978-0-13-288370-2.

2. Anil Kumar, S.; Suresh, N. Production and Operations Management (with Skill Development, Caselets and Cases); New Age International (P) Ltd.: New Delhi, India, 2008; ISBN 978-81-224-2177-4.

3. Chapman, S.N. The Fundamentals of Production Planning and Control; Pearson/Prentice Hall: Upper Saddle River, NJ, USA, 2006; ISBN 978-0-13-017615-8.

4. Stewart, J. The Toyota Kaizen Continuum: A Practical Guide to Implementing Lean, 1st ed.; CRC Press: Boca Raton, FL, USA, 2011; ISBN 978-1-4398-4605-6.

5. Rao, S.S. Engineering Optimization: Theory and Practice, 4th ed.; John Wiley \& Sons: Hoboken, NJ, USA, 2009; ISBN 978-0-470-18352-6.

6. Sarin, S.C.; Jaiprakash, P. Flow Shop Lot Streaming; Springer: New York, NY, USA; London, UK, 2007; ISBN 978-0-387-47687-2.

7. Welch, V.; Petticrew, M.; Petkovic, J.; Moher, D.; Waters, E.; White, H.; Tugwell, P. Extending the PRISMA Statement to Equity-Focused Systematic Reviews (PRISMA-E 2012): Explanation and Elaboration. Int. J. Equity Health 2015, 14, 92. [CrossRef]

8. Cheng, M.; Mukherjee, N.J.; Sarin, S.C. A Review of Lot Streaming. Int. J. Prod. Res. 2013, 51, 7023-7046. [CrossRef]

9. Chang, J.H.; Chiu, H.N. A Comprehensive Review of Lot Streaming. Int. J. Prod. Res. 2005, 43, 1515-1536. [CrossRef]

10. Gómez-Gasquet, P.; Segura-Andrés, R.; Andrés-Romano, C. A Review of Lot Streaming in a Flow Shop Environment with Makespan Criteria. JIEM 2013, 6, 761-770. [CrossRef]

11. Bagchi, T.P.; Gupta, J.N.D.; Sriskandarajah, C. A Review of TSP Based Approaches for Flowshop Scheduling. Eur. J. Oper. Res. 2006, 169, 816-854. [CrossRef]

12. Camara Gradim, L.C.; Archanjo Jose, M.; Marinho Cezar da Cruz, D.; de Deus Lopes, R. IoT Services and Applications in Rehabilitation: An Interdisciplinary and Meta-Analysis Review. IEEE Trans. Neural Syst. Rehabil. Eng. 2020, 28, $2043-2052$. [CrossRef] [PubMed] 
13. Diószegi, J.; Llanaj, E.; Ádány, R. Genetic Background of Taste Perception, Taste Preferences, and Its Nutritional Implications: A Systematic Review. Front. Genet. 2019, 10, 1272. [CrossRef] [PubMed]

14. Alam, S.A.N. Managing Organizational Knowledge by Unlearning? A Systematic Literature Review. In Proceedings of the 2019 International Conference on Computational Intelligence and Knowledge Economy (ICCIKE), IEEE, Dubai, United Arab Emirates, 11-12 December 2019; pp. 81-86.

15. Alarcón Palacios, M.; Ojeda Gómez, R.C.; Ticse Huaricancha, I.L.; Cajachagua Hilario, K. Análisis crítico de ensayos clínicos aleatorizados: Riesgo de sesgo. Rev. Estomatol. Herediana 2015, 25, 304-308. [CrossRef]

16. Higins, J.; Green, S. Updated March 2011; The Cochrane Collaboration: London, UK, 2011.

17. Yavuz, Y. Lot Streaming with Flexible Process Plans. Int. J. Prod. Res. 2013, 51, 5055-5072. [CrossRef]

18. Meng, T.; Pan, Q.-K.; Li, J.-Q.; Sang, H.-Y. An Improved Migrating Birds Optimization for an Integrated Lot-Streaming Flow Shop Scheduling Problem. Swarm Evol. Comput. 2018, 38, 64-78. [CrossRef]

19. Sang, H.-Y.; Pan, Q.-K.; Duan, P.-Y.; Li, J.-Q. An Effective Discrete Invasive Weed Optimization Algorithm for Lot-Streaming Flowshop Scheduling Problems. J. Intell. Manuf. 2018, 29, 1337-1349. [CrossRef]

20. Li, J.; Tao, X.; Jia, B.; Han, Y.; Liu, C.; Duan, P.; Zheng, Z.; Sang, H. Efficient Multi-Objective Algorithm for the Lot-Streaming Hybrid Flowshop with Variable Sub-Lots. Swarm Evol. Comput. 2020, 52, 100600. [CrossRef]

21. Alfieri, A.; Zhou, S.; Scatamacchia, R.; van de Velde, S.L. Dynamic Programming Algorithms and Lagrangian Lower Bounds for a Discrete Lot Streaming Problem in a Two-Machine Flow Shop. 4OR-Q J. Oper. Res. 2020, 19, 265-288. [CrossRef]

22. Pinedo, M. Scheduling: Theory, Algorithms, and Systems, 4th ed.; Springer: New York, NY, USA, 2012; ISBN 978-1-4614-1986-0.

23. Han, Y.; Gong, D.; Jin, Y.; Pan, Q. Evolutionary Multiobjective Blocking Lot-Streaming Flow Shop Scheduling with Machine Breakdowns. IEEE Trans. Cybern. 2019, 49, 184-197. [CrossRef] [PubMed]

24. Gong, D.; Han, Y.; Sun, J. A Novel Hybrid Multi-Objective Artificial Bee Colony Algorithm for Blocking Lot-Streaming Flow Shop Scheduling Problems. Knowl.-Based Syst. 2018, 148, 115-130. [CrossRef]

25. Han, Y.; Li, J.-Q.; Gong, D.; Sang, H. Multi-Objective Migrating Birds Optimization Algorithm for Stochastic Lot-Streaming Flow Shop Scheduling with Blocking. IEEE Access 2019, 7, 5946-5962. [CrossRef]

26. Han, Y.; Gong, D.; Jin, Y.; Pan, Q. Evolutionary Multi-Objective Blocking Lot-Streaming Flow Shop Scheduling with Interval Processing Time. Appl. Soft Comput. 2016, 42, 229-245. [CrossRef]

27. Han, Y.-Y.; Gong, D.; Sun, X.-Y.; Pan, Q.-K. An Improved NSGA-II Algorithm for Multi-Objective Lot-Streaming Flow Shop Scheduling Problem. Int. J. Prod. Res. 2014, 52, 2211-2231. [CrossRef]

28. Ventura, J.A.; Yoon, S.-H. A New Genetic Algorithm for Lot-Streaming Flow Shop Scheduling with Limited Capacity Buffers. J. Intell. Manuf. 2013, 24, 1185-1196. [CrossRef]

29. Chakaravarthy, G.V.; Marimuthu, S.; Sait, A.N. Performance evaluation of proposed Differential Evolution and Particle Swarm Optimization algorithms for scheduling m-machine flow shops with lot streaming. J. Intell. Manuf. 2013, 24, 175-191. [CrossRef]

30. Pan, Q.-K.; Ruiz, R. An Estimation of Distribution Algorithm for Lot-Streaming Flow Shop Problems with Setup Times. Omega 2012, 40, 166-180. [CrossRef]

31. Davendra, D.; Senkerik, R.; Zelinka, I.; Pluhacek, M.; Bialic-Davendra, M. Utilising the Chaos-Induced Discrete Self Organising Migrating Algorithm to Solve the Lot-Streaming Flowshop Scheduling Problem with Setup Time. Soft. Comput. 2014, 18, 669-681. [CrossRef]

32. Rossit, D.; Tohmé, F.; Frutos, M.; Bard, J.; Broz, D. A Non-Permutation Flowshop Scheduling Problem with Lot Streaming: A Mathematical Model. Int. J. Ind. Eng. Comput. 2016, 7, 507-516. [CrossRef]

33. Sang, H.; Gao, L.; Li, X. An Iterated Local Search Algorithm for the Lot-Streaming Flow Shop Scheduling Problem. Asia Pac. J. Oper. Res. 2014, 31, 1450045. [CrossRef]

34. Fang, K.; Luo, W.; Che, A. Speed Scaling in Two-Machine Lot-Streaming Flow Shops with Consistent Sublots. J. Oper. Res. Soc. 2020, 71, 1-13. [CrossRef]

35. Pan, Q.-K.; Suganthan, P.N.; Liang, J.J.; Tasgetiren, M.F. A Local-Best Harmony Search Algorithm with Dynamic Sub-Harmony Memories for Lot-Streaming Flow Shop Scheduling Problem. Expert Syst. Appl. 2011, 38, 3252-3259. [CrossRef]

36. Pan, Q.-K.; Wang, L.; Gao, L.; Li, J. An Effective Shuffled Frog-Leaping Algorithm for Lot-Streaming Flow Shop Scheduling Problem. Int. J. Adv. Manuf. Technol. 2011, 52, 699-713. [CrossRef]

37. Pan, Q.-K.; Fatih Tasgetiren, M.; Suganthan, P.N.; Chua, T.J. A Discrete Artificial Bee Colony Algorithm for the Lot-Streaming Flow Shop Scheduling Problem. Inf. Sci. 2011, 181, 2455-2468. [CrossRef]

38. Ferraro, A.; Rossit, D.; Toncovich, A.; Frutos, M. Lot Streaming Flow Shop with a Heterogeneous Machine. Eng. Manag. J. 2019, 31, 113-126. [CrossRef]

39. Wang, H.; Zhao, F.; Gao, H.; Sutherland, J.W. A Three-Stage Method with Efficient Calculation for Lot Streaming Flow-Shop Scheduling. Front. Inf. Technol. Electron. Eng. 2019, 20, 1002-1020. [CrossRef]

40. Ramesh, C.; Kamalakannan, R.; Karthik, R.; Pavin, C.; Dhivaharan, S. A Lot Streaming Based Flow Shop Scheduling Problem Using Simulated Annealing Algorithm. Mater. Today Proc. 2021, 37, 241-244. [CrossRef]

41. Mukherjee, N.J.; Sarin, S.C.; Singh, S. Lot Streaming in the Presence of Learning in Sublot-Attached Setup Times and Processing Times. Int. J. Prod. Res. 2017, 55, 1623-1639. [CrossRef]

42. Mortezaei, N.; Zulkifli, N. Integration of Lot Sizing and Flow Shop Scheduling with Lot Streaming. J. Appl. Math. 2013, 2013, 216595. [CrossRef] 
43. Li, Y.G.; Zhang, M.S. A Multi-Objective Lot-Streaming Optimization Scheduling Model Considering the Blocking Effect. Int. J. Simul. Model. 2016, 16, 731-741. [CrossRef]

44. Sang, H.; Gao, L.; Pan, Q. Discrete Artificial Bee Colony Algorithm for Lot-Streaming Flowshop with Total Flowtime Minimization. Chin. J. Mech. Eng. 2012, 25, 990-1000. [CrossRef]

45. Fattahi, P.; Azizi, V.; Jabbari, M. Lot Streaming in No-Wait Multi Product Flowshop Considering Sequence Dependent Setup Times and Position Based Learning Factors. IJE 2015, 28, 1031-1039. [CrossRef]

46. Yoon, S.-H. Minimizing the Total Stretch when Scheduling Flows of Divisible Requests without Interruption. J. Soc. E-Bus. Stud. 2015, 20, 79-88. [CrossRef]

47. Defersha, F.M.; Chen, M. A Genetic Algorithm for One-Job m-Machine Flowshop Lot Streaming with Variable Sublots. IJOR 2011, 10, 458. [CrossRef]

48. Glass, C.A.; Possani, E. Lot Streaming Multiple Jobs in a Flow Shop. Int. J. Prod. Res. 2011, 49, 2669-2681. [CrossRef]

49. Mortezaei, N.; Zulkifli, N. A Study on Integration of Lot Sizing and Flow Shop Lot Streaming Problems. Arab. J. Sci. Eng. 2014, 39, 9283-9300. [CrossRef]

50. Mortezaei, N.; Norzima, Z.; Tang, S.H.; Rosnah, M.Y. Lot Streaming and Preventive Maintenance in a Multiple Product Permutation Flow Shop with Intermingling. AMM 2014, 564, 689-693. [CrossRef]

51. Mortezaei, N.; Zulkifli, N. Mixed-Integer Formulation for Integration of Lot Sizing and Lot Streaming Problem with Scheduled Preventive Maintenance. RJASET 2014, 7, 2563-2568. [CrossRef]

52. Davendra, D.; Senkerik, R.; Zelinka, I.; Pluhacek, M.; Bialic-Davendra, M. Utilising the Chaos-Induced Discrete Self Organising Migrating Algorithm to Schedule the Lot-Streaming Flowshop Scheduling Problem with Setup Time. In Nostradamus 2013: Prediction, Modeling and Analysis of Complex Systems; Zelinka, I., Chen, G., Rössler, O.E., Snasel, V., Abraham, A., Eds.; Advances in Intelligent Systems and Computing; Springer International Publishing: Berlin/Heidelberg, Germany, 2013; Volume 210, pp. 31-45, ISBN 978-3-319-00541-6.

53. Yang, L.; Pan, Y.X. Discrete Particle Swarm Optimization Algorithm for Lot-Streaming No-Wait Flow Shop Scheduling Problem. AMR 2012, 538-541, 863-868. [CrossRef]

54. Defersha, F.M.; Chen, M. A Hybrid Genetic Algorithm for Flowshop Lot Streaming with Setups and Variable Sublots. Int. J. Prod. Res. 2010, 48, 1705-1726. [CrossRef]

55. Alfieri, A.; Glass, C.; van de Velde, S. Two-Machine Lot Streaming with Attached Setup Times. IIE Trans. 2012, 44, 695-710. [CrossRef]

56. Han, H.Y. The Lot-Streaming Flow Scheduling Shops Based on a Hybrid Discrete Harmony Search Algorithm. AMR 2011, 204-210, 563-568. [CrossRef]

57. Nejati, M.; Mahdavi, I.; Hassanzadeh, R.; Mahdavi-Amiri, N. Lot Streaming in a Two-Stage Assembly Hybrid Flow Shop Scheduling Problem with a Work Shift Constraint. J. Ind. Prod. Eng. 2016, 33, 459-471. [CrossRef]

58. Chen, T.-L.; Cheng, C.-Y.; Chou, Y.-H. Multi-Objective Genetic Algorithm for Energy-Efficient Hybrid Flow Shop Scheduling with Lot Streaming. Ann. Oper. Res. 2020, 290, 813-836. [CrossRef]

59. Cheng, M.; Sarin, S.C.; Singh, S. Two-Stage, Single-Lot, Lot Streaming Problem for a $\$ \$ 1+2 \$ \$ 1+2$ Hybrid Flow Shop. J. Glob. Optim. 2016, 66, 263-290. [CrossRef]

60. Wang, P.; Sang, H.; Tao, Q.; Guo, H.; Li, J.; Gao, K.; Han, Y. Improved Migrating Birds Optimization Algorithm to Solve Hybrid Flowshop Scheduling Problem with Lot-Streaming. IEEE Access 2020, 8, 89782-89792. [CrossRef]

61. Defersha, F.M.; Chen, M. Mathematical Model and Parallel Genetic Algorithm for Hybrid Flexible Flowshop Lot Streaming Problem. Int. J. Adv. Manuf. Technol. 2012, 62, 249-265. [CrossRef]

62. Cheng, M.; Sarin, S.C. Lot Streaming in a Two-Stage Assembly System. Annu. Rev. Control. 2020, 50, 303-316. [CrossRef]

63. Wang, S.; Kurz, M.; Mason, S.J.; Rashidi, E. Two-Stage Hybrid Flow Shop Batching and Lot Streaming with Variable Sublots and Sequence-Dependent Setups. Int. J. Prod. Res. 2019, 57, 6893-6907. [CrossRef]

64. Nejati, M.; Mahdavi, I.; Hassanzadeh, R.; Mahdavi-Amiri, N.; Mojarad, M. Multi-Job Lot Streaming to Minimize the Weighted Completion Time in a Hybrid Flow Shop Scheduling Problem with Work Shift Constraint. Int. J Adv. Manuf. Technol. 2014, 70, 501-514. [CrossRef]

65. Zhang, B.; Pan, Q.; Gao, L.; Zhang, X.; Sang, H.; Li, J. An Effective Modified Migrating Birds Optimization for Hybrid Flowshop Scheduling Problem with Lot Streaming. Appl. Soft Comput. 2017, 52, 14-27. [CrossRef]

66. Defersha, F.M. A Simulated Annealing with Multiple-Search Paths and Parallel Computation for a Comprehensive Flowshop Scheduling Problem: A Simulated Annealing with Multiple-Search Paths and Parallel Computation for a Comprehensive Flowshop Scheduling Problem. Intl. Trans. Op. Res. 2015, 22, 669-691. [CrossRef]

67. Defersha, F.M. A Comprehensive Mathematical Model for Hybrid Flexible Flowshop Lot Streaming Problem. IJIEC 2011, 2, 283-294. [CrossRef]

68. Lalitha, J.L.; Mohan, N.; Pillai, V.M. Lot Streaming in [N-1] (1) + N (m) Hybrid Flow Shop. J. Manuf. Syst. 2017, 44, 12-21. [CrossRef]

69. Lei, D.; Guo, X. Scheduling Job Shop with Lot Streaming and Transportation through a Modified Artificial Bee Colony. Int. J. Prod. Res. 2013, 51, 4930-4941. [CrossRef]

70. Güçdemir, H.; Selim, H. Integrating Simulation Modelling and Multi Criteria Decision Making for Customer Focused Scheduling in Job Shops. Simul. Model. Pract. Theory 2018, 88, 17-31. [CrossRef] 
71. López, M.L.N.; Díaz, H.L.; Sanmiguel, P.J.J.; González, J.V.R. Transfer Batch Size Impact on a Job Shop Environment Performance. IJMR 2017, 12, 318. [CrossRef]

72. Xu, X.Q.; Lei, D.M. Research on Swarm Intelligence Algorithm with an Artificial Bee Colony Algorithm for Lot Streaming Problem in Job Shop. AMR 2014, 951, 239-244. [CrossRef]

73. Liu, C.-H.; Chen, L.-S.; Lin, P.-S. Lot Streaming Multiple Jobs with Values Exponentially Deteriorating over Time in a Job-Shop Environment. Int. J. Prod. Res. 2013, 51, 202-214. [CrossRef]

74. Bożek, A.; Werner, F. Flexible Job Shop Scheduling with Lot Streaming and Sublot Size Optimisation. Int. J. Prod. Res. 2018, 56, 6391-6411. [CrossRef]

75. Novas, J.M. Production Scheduling and Lot Streaming at Flexible Job-Shops Environments Using Constraint Programming. Comput. Ind. Eng. 2019, 136, 252-264. [CrossRef]

76. Zhang, S.; Li, X.; Zhang, B.; Wang, S. Multi-Objective Optimisation in Flexible Assembly Job Shop Scheduling Using a Distributed Ant Colony System. Eur. J. Oper. Res. 2020, 283, 441-460. [CrossRef]

77. Yousefi Yegane, B.; Nakhai Kamalabadia, I.; Khanlarzade, N. Critical Path Method for Lot Streaming Problem in Flexible Job Shop Environment. IJE 2017, 30, 216-269. [CrossRef]

78. Kesen, S.E.; Güngör, Z. How Important Is the Batch Splitting Activity in Scheduling of Virtual Manufacturing Cells (VMCs)? Int. J. Prod. Res. 2011, 49, 1645-1667. [CrossRef]

79. Almeder, C.; Klabjan, D.; Traxler, R.; Almada-Lobo, B. Lead Time Considerations for the Multi-Level Capacitated Lot-Sizing Problem. Eur. J. Oper. Res. 2015, 241, 727-738. [CrossRef]

80. Ye, T. Analysis on Multi-Stage Lot Streaming: The Effect of Transfer. Comput. Ind. Eng. 2012, 62, 1046-1054. [CrossRef]

81. Sun, Y. Fuzzy Approaches and Simulation-Based Reliability Modeling to Solve a Road-Rail Intermodal Routing Problem with Soft Delivery Time Windows When Demand and Capacity Are Uncertain. Int. J. Fuzzy Syst. 2020, 22, 2119-2148. [CrossRef]

82. Kovács, P. Minimum-Cost Flow Algorithms: An Experimental Evaluation. Optim. Methods Softw. 2015, 30, 94-127. [CrossRef] 